\title{
Reconciling energy efficiency and energy intensity metrics: an integrated decomposition analysis
}

\author{
Ralph D. Torrie (iD • Christopher Stone • David B. Layzell
}

Received: 3 October 2017 / Accepted: 19 April 2018 / Published online: 8 May 2018

(C) The Author(s) 2018

\begin{abstract}
We develop and illustrate a method for reconciling index decomposition analysis of energy intensity with physically based, sector-specific energy efficiency indicators. Decomposition analysis of individual sector intensity contributions to total energy intensity is nested within the higher-order decomposition analysis of $E /$ GDP such that the contribution of energy efficiency gains to changes in total energy intensity can be determined. Energy, economic and physical activity data for Canada for the period 1995-2010 are used to illustrate the method. Intrasector structural factors were found to be both positive and negative and to be significant contributors to energy intensities in both the business and household sectors. In aggregate, intrasectoral structural change offset energy efficiency gains and put
\end{abstract}

Electronic supplementary material The online version of this article (https://doi.org/10.1007/s12053-018-9667-z) contains supplementary material, which is available to authorized users.

R. D. Torrie $(\bowtie)$

Torrie Smith Associates, 125 Perry Street, Cobourg, ON K9A 1N8, Canada

e-mail: rtorrie@torriesmith.com

C. Stone · D. B. Layzell

Canadian Energy Systems Analysis Research (CESAR) Initiative, University of Calgary, Calgary, AB T2N 1N4, Canada

C. Stone

e-mail: chris-stone@ outlook.com

D. B. Layzell

e-mail: dlayzell@ucalgary.ca upward pressure on (E/GDP) between 1995 and 2010 but was three times smaller than the offsetting decline in E/GDP due to intersectoral structural change. The method can be used for assessing the contribution of energy efficiency to sector energy intensities; for placing energy efficiency policies in the larger context of the other factors that determine an economy's energy intensity and greenhouse gas emissions; for identifying nonefficiency policy targets for improving energy productivity; and for increasing the sophistication of forecasting and scenario analysis of future levels and patterns of fuel and electricity consumption and related greenhouse gas emissions.

Keywords Decomposition analysis · Energy intensity · Energy efficiency. Canada

\section{Introduction}

Energy intensity (primary energy consumption per dollar of GDP $(E / G D P))$ is a key determinant of greenhouse gas emissions, and understanding the dynamics of the $E /$ GDP quotient is of central importance for informing policies for climate change mitigation and for anticipating changes in the level and pattern of fuel and electricity use. Of particular interest are the contributions of energy efficiency and structural change to overall change in energy intensity $\Delta(E / G D P)$, and this requires distinguishing physical energy intensity from structural change at the intrasector level (Kerimray et al. 2017; Bashmakov and Myshak 2014). 
Our objective is to describe and illustrate a method for quantifying the energy efficiency and structural components of changes in energy intensity $(\Delta(E / \mathrm{GDP})$ so as to better inform policy, program evaluation and energy forecasting. Energy intensity is easily quantified with economic and energy data that is readily available in most countries and is sometimes conflated with energy efficiency (Moshiri and Duah 2016; Andreoni and Galmarini 2016; Colinet Carmona and Román Collado 2016; Fernández González 2015; Moutinho et al. 2016). ${ }^{1}$ However, energy intensity is a complex variable that is influenced by other factors that can augment or offset energy efficiency gains. These factors include the composition of output, per capita GDP and real prices. The reconciliation of $E / G D P$ and energy efficiency is a recognised issue in decomposition analysis (Belzer et al. 2017; IEA 2016).

The proposed method is demonstrated using data from Canada for the period 1995-2010. During this period, the ratio of total primary energy use to GDP in Canada declined by $23 \%(2.64 \mathrm{MJ} / \$)$ from 11.24 to $8.6 \mathrm{MJ} / \$$, establishing it as the principal source of downward pressure on greenhouse gas emissions during a period when population and per capita GDP were growing and the carbon intensity of the energy supply declined only slightly (Fig. 1).

The results of a first-order decomposition analysis (Torrie et al. 2016) show that $72 \%$ of the total $\Delta$ (E/GDP) was associated with intersector structural changes in the economy plus a per capita GDP impact, ${ }^{2}$ as summarised in Fig. 2a. The remaining $28 \%(-0.75 \mathrm{MJ} / \$)$ is attributed to improvements in the sector energy intensities of businesses or households in Canada (Fig. 2b). The analysis also shows large variations between sectors in their contributions to the total change in the energy intensity of the Canadian economy (Fig. 2c).

\footnotetext{
${ }^{1}$ More precisely, it is the inverse of energy intensity (GDP/E) that is sometimes conflated with or defined as energy efficiency. In this paper, energy efficiency is defined more narrowly, at the sector level, as the inverse of the amount of fuel and electricity consumed per unit of physical activity, with the activity unit being sector dependent. This definition is developed more fully in the 'Methodology' section of the paper.

${ }^{2}$ The 'per capita GDP' impact on $\Delta(E / G D P)$ reflects the relatively large share of total energy use that is not directly employed in the generation of GDP. The residential and personal transportation sectors account for about a third of Canadian energy use, and for these two sectors, we define energy intensity in per capita terms rather than per GDP terms. In this framework, an increase in per capita GDP will result in a decrease in total $E / G D P$, even in the absence of any changes in per capita residential or personal transportation energy intensities.
}

The contribution of energy efficiency to $\Delta(E / \mathrm{GDP})$ is embedded in the individual sector intensity contributions illustrated in Fig. 2c, and the focus of this paper is the decomposition of each of these sector impacts, where data permits, into structure and physical intensity (efficiency) components. The contributions of sector energy intensity changes identified in the first-order decomposition analysis of Canadian E/GDP over the 19952010 period are themselves subject to decomposition analysis to separate efficiency from intrasectoral structural factors (for example, larger dwellings, intrasectoral shifts in product mix, changes in floor area requirements in the tertiary sector etc.). This analysis is then nested within the original economy-wide decomposition analysis to produce a single, comprehensive and internally consistent breakdown of efficiency and structural contributions to changes in primary energy intensity.

The next section describes the method used for the sector decomposition anlayses and their integration in the first order analysis. This is followed by a sector-bysector presentation and discussion of results. Conclusions and policy implications are presented in the final section of the paper.

\section{Methodology}

This study builds on the results of a first-order decomposition analysis of Canadian primary energy intensity (Torrie et al. 2016) that applies the Logarithmic Mean Divisia Index (LMDI) method (Ang 2004, 2015; Ang and Liu 2001; Ang et al. 2010; Su and Ang 2012; Xu and Ang 2014; Ang and Wang 2015) to produce a comprehensive and internally consistent decomposition of total $\Delta(E / G D P)$ in Canada for the 1995-2010 period.

The LMDI method has emerged as the preferred method for energy decomposition analysis at the level of sectors (Olanrewaju 2017; Norman 2017; Ang and $\mathrm{Xu}$ 2013), countries (Wang and Feng 2017; Sumabat et al. 2016; Cansino et al. 2015; Oh et al. 2010; O'Mahony et al. 2012; Zhang et al. 2016; Kerimray et al. 2017) and multi-country comparisons (Reutters et al. 2017; Andreoni and Galmarini 2016; Fernández González 2015; Moutinho et al. 2016; Bataille et al. 2007). The typical LMDI application involves factoring energy (or emissions), with energy intensity as one of the factors. This approach identifies the contribution that changes in energy intensity make to trends in energy (or emissions) but does not address the question of the 


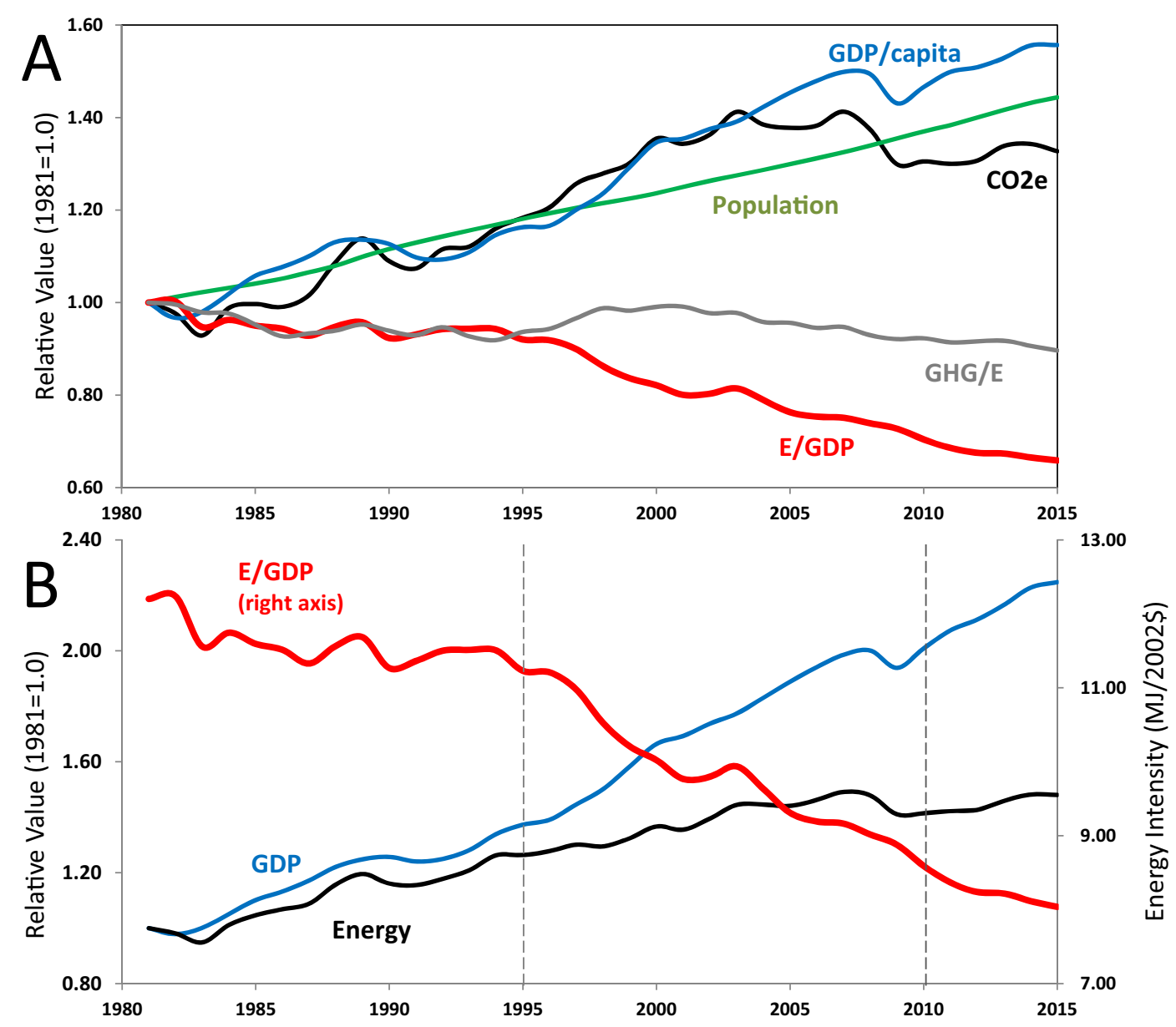

Fig. 1 a Changes in Kaya factors for energy-based GHG emissions in Canada, 1981-2015, where $\mathrm{CO}_{2} \mathrm{e}(\mathrm{Mg})=$ population (capita) $\times$ GDP / population (\$/capita) $\times$ energy use / GDP $(\mathrm{GJ} /$

extent to which the change in energy intensity is the result of changes in the physical efficiency of energy use.

Some LMDI decomposition analyses focus on energy intensity rather than energy (Kerimray et al. 2017), and this study uses the results of one such intensity decomposition analysis (Torrie et al. 2016) that identifies the contributions individual sector intensity changes make to total $\Delta(E / \mathrm{GDP})$ of the economy. As described in more detail below, the sector intensities are subjected to further LMDI decomposition to specify the separate contributions of energy efficiency (changes in physical energy intensity) from other influences on energy intensity.

Table 1 contains the sector definitions. The previous study found that sector intensity changes accounted for $28 \%$ of total $\Delta(E / G D P)$ over the study period (see Fig. 2 ), and in this report, we describe the application of the
$\$) \times \mathrm{GHG} /$ energy use $\left(\mathrm{MgCO}_{2} \mathrm{e} / \mathrm{GJ}\right)$. b Primary energy intensity (MJ/2002\$) of Canadian economy, 1981-2015

LMDI method to each of the sector intensity contributions to $\Delta(E / \mathrm{GDP})$. This is a variation on a method also used by the Canadian federal government for energy demand trend analysis (NRCan 2016; Palmer 2003), but in this analysis, all the sector intensity changes are analysed in a single computational framework that allows the results to be added, compared and integrated with the first order decomposition analysis of $\Delta(E /$ GDP).

The strategy for the decomposition analysis varies for each sector in response to the characteristics of that sector and the availability of data. The data for the analysis are available in the Online resources and were obtained from Statistics Canada (2015a, b), CIEEDAC (2015), and whatIf? Technologies (2015), owners of the Canadian Energy Systems Simulator (CanESS). Where available data permits, sectors are reduced to subsectors 


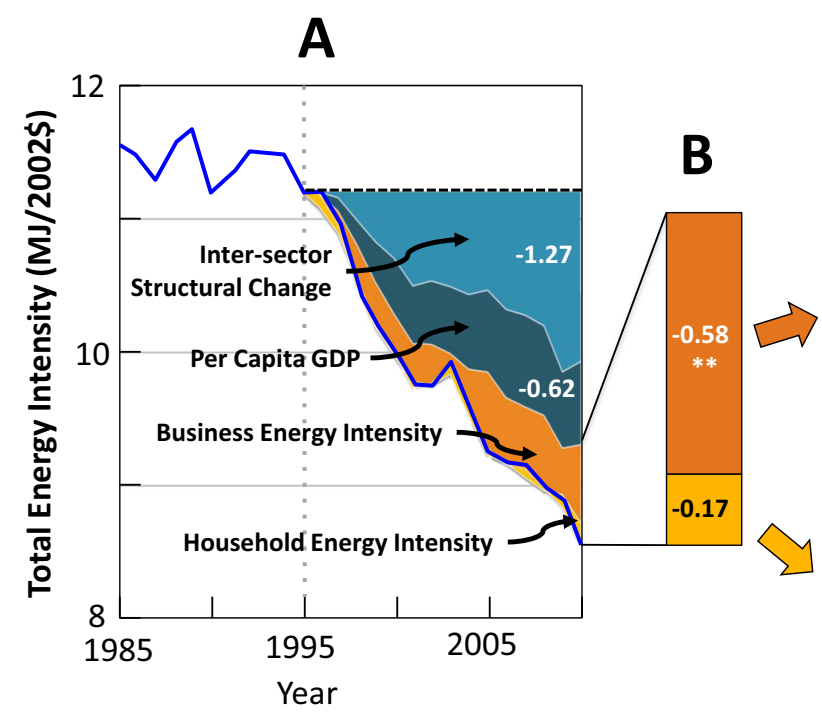

Fig. 2 Decomposition of the observed change in Canada's energy/GDP quotient between 1995 and 2010 (a), showing the contribution of a net change in business and household energy

(e.g. oil and gas; energy-intensive industries) for further decomposition analysis.

The key methodological innovation is the definition of 'physical activity drivers' (described in more detail below) for each sector and subsector that facilitate the decomposition analysis of intrasectoral structural and energy efficiency impacts on $\Delta(E / G D P)$.

Physical activity drivers

To support factorisation of sector energy intensity changes into structural and energy efficiency components, physical activity drivers (PADs) are defined for each sector or subsector (where possible), as summarised in Tables 2 and 3. Each business or household sector varies in the extent to which data support the definition of subsectors, PADs or other factors that can be used to understand the forces contributing to the total energy intensity of the Canadian economy. The method relies upon a one-to-one correspondence of the energy, GDP and PAD datasets. Energy and economic datasets will generally not support perfect mapping of energy use to GDP categories, but the mapping will support

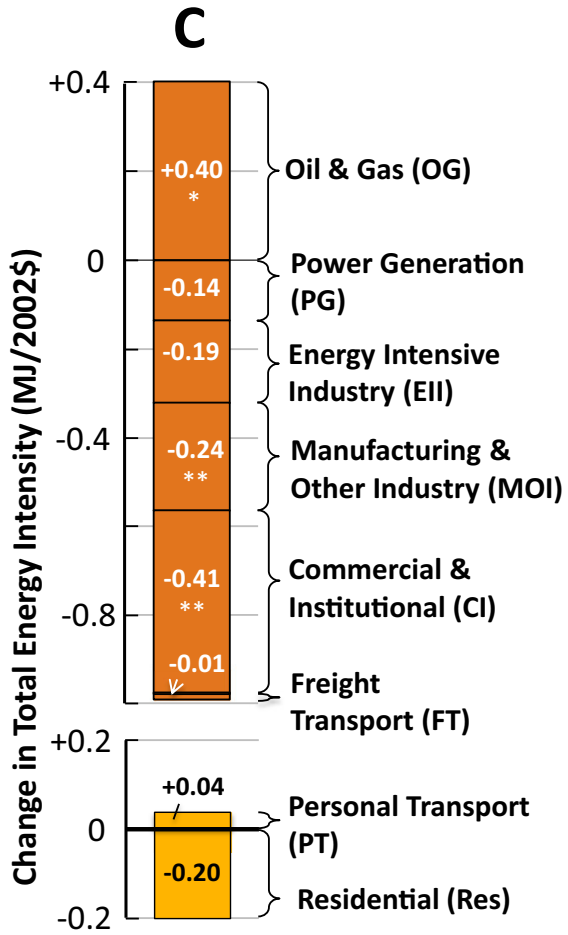

intensity (b) which was subsequently decomposed into sector contributions (c). Adapted from Torrie et al. (2016)

decomposition analysis of $\Delta(E / G D P)$ if discrepancies between the category definitions in the databases are small $^{3}$ and if residential and personal transportation energy use are left out of the direct GDP mapping. Factorisation of the PAD dynamics only proceeds for sectors or subsectors for which we have mutually consistent PAD, GDP and energy consumption data.

For each business sector (Table 2), the sector energy intensity $\left(E_{i}\right.$, the energy use of sector $i$, divided by $\mathrm{GDP}_{i}$, the GDP generated by sector $i$ ) is factored:

$\frac{E_{i}}{\mathrm{GDP}_{i}}=\frac{E_{i}}{\mathrm{PAD}_{i}} \times \frac{\mathrm{PAD}_{i}}{\mathrm{GDP}_{i}}$

The first factor represents the physical energy intensity of the sector and the second factor represents the relationship of the physical driver (PAD) to the economic output (GDP) of the sector.

\footnotetext{
${ }^{3}$ For example, public transit energy use is included in the residential energy use sector, even though its contribution to GDP is included in the CI sector of the business economy. In this case, it is more helpful to include public transit in the decomposition of per capita personal transportation energy use. In Canada, its contributions to GDP and $\mathrm{CI}$ energy use are too small $(<1 \%)$ to significantly affect the decomposition analysis of E/GDP in the CI sector.
} 
Table 1 Sector definitions for decomposition analysis

\begin{tabular}{|c|c|c|}
\hline Index $i$ & Sector & Description (NAICS codes in brackets) \\
\hline \multicolumn{3}{|c|}{ Business economy sectors } \\
\hline OG & Oil and gas industry & $\begin{array}{l}\text { Oil and gas extraction }(211,213) \text {, refineries }(324) \text { and pipelines } \\
\text { (486). Production includes conventional oil and gas (211113) and } \\
\text { nonconventional oil (21114) }\end{array}$ \\
\hline PG & Power generation & Electricity production from all sources (2211) \\
\hline EII & Energy intensive industry & $\begin{array}{l}\text { Mining (212), aluminium smelting (3313), steel making (3311, 3312), } \\
\text { primary metals smelting (3314), cement making (3273), pulp and paper (3221) } \\
\text { and energy intensive chemical production }(3251,3252 \text { and } 3253)\end{array}$ \\
\hline MOI & Manufacturing and other industry & $\begin{array}{l}\text { This is a residual category that includes all manufacturing not included elsewhere, } \\
\text { plus agriculture, fishing, forestry and construction (NAIC codes } 11-39 \text { unless } \\
\text { specified above as part of the oil and gas, electric power or energy intensive } \\
\text { manufacturing sectors.) }\end{array}$ \\
\hline $\mathrm{CI}$ & Commercial and institutional & $\begin{array}{l}\text { Including offices, retail, education, hospitals, warehouses, water and sewage } \\
\text { utilities, other building types ( } 41 \text { through } 91 \text {, unless specified as part of } \\
\text { other sectors). }\end{array}$ \\
\hline FT & Freight transportation & $\begin{array}{l}\text { Truck, rail, air, marine (48 and } 49 \text { except pipelines (486) which are included as part } \\
\text { of the oil and gas sector and warehouses (493) which are included as part of the } \\
\text { commercial and institutional sector). }\end{array}$ \\
\hline \multicolumn{3}{|c|}{ Household sectors } \\
\hline Res & Residential & $\begin{array}{l}\text { Four subsectors defined by dwelling type: single family detached, attached, } \\
\text { apartments, and other. }\end{array}$ \\
\hline PT & Personal transportation & Car, truck, air, rail, public transit, other modes, non-motorised \\
\hline
\end{tabular}

For the household sectors (Table 3), the per capita energy intensity for residential energy use $(r)$ and personal transport $(t)$ is factored as follows

$$
\begin{gathered}
\frac{E_{r}}{\text { capita }}=\frac{E_{r}}{\mathrm{PAD}_{r}} \times \frac{\mathrm{PAD}_{r}}{\text { capita }} \\
\frac{E_{t}}{\text { capita }}=\frac{E_{t}}{\mathrm{PAD}_{t}} \times \frac{\mathrm{PAD}_{t}}{\text { capita }}
\end{gathered}
$$

The introduction of the PAD allows the sector energy intensities to be expressed as the products of factors related to physical energy intensities $\left(E_{i} / \mathrm{PAD}_{i}, E_{r} / \mathrm{PAD}_{r}\right.$, $\left.E / \mathrm{PAD}_{\mathrm{t}}\right)$ and $\mathrm{PAD}_{i} / \mathrm{GDP}_{i}$ relationships, as detailed in Tables 2 and 3. The factored equations in Tables 2 and 3 are variations on generalised compound energy intensity $\frac{E}{Q}=\sum_{i}\left(\frac{E_{i}}{Q_{i}} \times \frac{Q_{i}}{Q}\right)$ to which LMDI decomposition analysis can be applied to determine the contributions of changes in $E_{i} / Q_{i}$ and changes in $Q_{i} / Q$ to an overall $\Delta(E /$ $Q$ ) between time $T_{1}$ and $T_{2}$ such that:

$$
\Delta\left(\frac{E}{Q}\right)_{T_{1}}^{T_{2}}=\Delta\left(\frac{E}{Q}\right)_{\text {from } \Delta\left(\frac{E_{i}}{Q_{i}}\right)}+\Delta\left(\frac{E}{Q}\right)_{\text {from } \Delta\left(\frac{Q_{i}}{Q}\right)}
$$

Where

$$
\Delta\left(\frac{E}{Q}\right)_{\text {from } \Delta\left(\frac{E_{i}}{Q_{i}}\right)}=\sum_{i} L\left(\left(\frac{E_{i}}{Q}\right)^{T_{2}},\left(\frac{E_{i}}{Q}\right)^{T_{1}}\right) \ln \left(\frac{\left(E_{i} / Q_{i}\right)^{T_{2}}}{\left(E_{i} / Q_{i}\right)^{T_{1}}}\right)
$$

And

$$
\Delta\left(\frac{E}{Q}\right)_{\text {from } \Delta\left(\frac{Q_{i}}{Q}\right)}=\sum_{i} L\left(\left(\frac{E_{i}}{Q}\right)^{T_{2}},\left(\frac{E_{i}}{Q}\right)^{T_{1}}\right) \ln \left(\frac{\left(Q_{i} / Q\right)^{T_{2}}}{\left(Q_{i} / Q\right)^{T_{1}}}\right)
$$

and where the logarithmic mean $L$ is defined as:

$$
L(a, b)=\frac{a-b}{\ln (a / b)}, \text { for } a \neq b
$$

and $L(a, b)=0$ when $a=b(8)$

We conduct chained LMDI decomposition analysis of the changes in sectoral energy intensities, with the analysis proceeding in stages according to the level of disaggregation permitted by the available data. Details 
Table 2 Business Sector energy intensity factorisation

Business Sector energy intensity factorisation

\begin{tabular}{|c|c|}
\hline Sectors & Equations \\
\hline \multicolumn{2}{|c|}{ Business sectors (factorisation based on $E_{i} / \mathrm{GDP}_{i}$ ) } \\
\hline Oil and gas (OG) & $\frac{E_{\mathrm{OG}}}{\mathrm{GDP}_{\mathrm{OG}}}=\sum_{j}\left(\frac{E_{j}}{\mathrm{GDP}_{j}} \times \frac{\mathrm{GDP}_{j}}{\mathrm{GDP}_{\mathrm{OG}}}\right)$ \\
\hline Extraction $(j=\mathrm{ext})$ & $\frac{E_{\mathrm{ext}}}{\mathrm{GDP}_{\mathrm{ext}}}=\frac{\mathrm{Eo}_{\mathrm{ext}}}{\mathrm{GDP}_{\mathrm{ext}}} \times \sum_{k}\left(\left(\frac{E_{\mathrm{ext}}}{\mathrm{Eo}_{\mathrm{ext}}}\right)_{k} \times \frac{\left(\mathrm{Eo}_{\mathrm{ext}}\right)_{k}}{\mathrm{Eo}_{\mathrm{ext}}}\right)$ \\
\hline Pipelines $(j=\mathrm{pl})$ & $\frac{E_{\mathrm{pl}}}{\mathrm{GDP}_{\mathrm{pl}}}=\frac{\mathrm{Eo}_{\mathrm{pl}}}{\mathrm{GDP}_{\mathrm{pl}}} \times \sum_{l}\left(\left(\frac{E_{\mathrm{pl}}}{\mathrm{Eo}_{\mathrm{pl}}}\right)_{l} \times \frac{\left(\mathrm{Eo} \mathrm{pl}_{l}\right)_{l}}{E o_{p l}}\right)$ \\
\hline $\begin{array}{l}\text { Oil refineries } \\
(i=\mathrm{ref})\end{array}$ & $\frac{E_{\text {ref }}}{\mathrm{GDP}_{\text {ref }}}=\frac{E_{\text {ref }}}{\mathrm{GDP}_{\text {ref }}} \times \frac{E_{\text {ref }}}{\mathrm{Eo}_{\text {ref }}}$ \\
\hline $\begin{array}{l}\text { Power generation } \\
\text { (PG) }\end{array}$ & $\frac{E_{\mathrm{PG}}}{\mathrm{GDP}_{\mathrm{PG}}}=\frac{\mathrm{Eo}_{\mathrm{PG}}}{\mathrm{GDP}_{\mathrm{PG}}} \times \sum_{m}\left(\left(\frac{E_{\mathrm{PG}}}{\mathrm{EO}_{\mathrm{PG}}}\right)_{m} \times \frac{\left(\mathrm{Eo}_{\mathrm{PG}}\right)_{m}}{\mathrm{EO}_{\mathrm{PG}}}\right)$ \\
\hline
\end{tabular}

Energy intensive industry (EII)

$$
\frac{E_{\mathrm{EII}}}{\mathrm{GDP}_{\mathrm{EII}}}=\sum_{n}\left(\frac{E_{n}}{\mathrm{GDP}_{n}} \times \frac{\mathrm{GDP}_{n}}{\mathrm{GDP}_{\mathrm{EII}}}\right)
$$

Manufacturing and other industry (MOI)

Commercial and institutional $(\mathrm{CI})$

$$
\frac{E_{\mathrm{CI}}}{\mathrm{GDP}_{\mathrm{CI}}}=\frac{A_{\mathrm{CI}}}{\mathrm{GDP}_{\mathrm{CI}}} \times \sum_{p}\left(\left(\frac{E_{\mathrm{CI}}}{A_{\mathrm{CI}}}\right)_{p} \times \frac{\left(A_{\mathrm{CI}}\right)_{p}}{A_{\mathrm{CI}}}\right)
$$

Freight transport

$$
\frac{E_{\mathrm{FT}}}{\mathrm{GDP}_{\mathrm{FT}}}=\frac{\mathrm{TKT}}{\mathrm{GDP}_{\mathrm{FT}}} \times \sum_{q}\left(\left(\frac{E_{\mathrm{FT}}}{\mathrm{TKT}}\right)_{q} \times \frac{\mathrm{TKT}_{q}}{\mathrm{TKT}}\right)
$$

Factors, subsector and index definitions

Energy intensities $\left(E_{j} / \mathrm{GDP}_{j}\right)$ for $j$ subsectors where $J$ is extraction (ext), pipelines $(\mathrm{pl})$ or refineries (ref).

$\mathrm{PAD} \equiv$ production output $\left(\mathrm{Eo}_{\mathrm{ext}}, \mathrm{PJ}\right)$ and energy used in resource extraction $\left(E_{\text {ext }}, \mathrm{PJ}\right)$ for $k$ resources where $k$ is conventional oil, unconventional oil or natural gas.

$\mathrm{PAD} \equiv$ Product piped $\left(\mathrm{Eo}_{\mathrm{pl}}, \mathrm{PJ}\right)$ and energy used in pipelining resource $\left(E_{\mathrm{pl}}, \mathrm{PJ}\right)$ for $l$ products where $l=$ oil or gas.

$\mathrm{PAD} \equiv$ crude oil refined $\left(\mathrm{Eo}_{\text {ref }}, \mathrm{PJ}\right)$ and energy used by oil refineries

$\mathrm{PAD} \equiv$ electricity produced $\left(E_{\mathrm{oPG}}, \mathrm{kWh}\right)$ for $m$ types of power plant/fuel combinations. The primary energy consumption of power generation $\left(E_{\mathrm{PG}}\right)$ is the sum of the primary energy consumed by the different types of power plants. For fossil fuel generation, it is the difference between the fuel inputs and the electricity produced. For hydro, solar and wind, $E_{\mathrm{PG}}$ is assumed to equal $E_{\mathrm{oPG}}$. For nuclear power, $E_{\mathrm{PG}}$ is assumed to equal $E_{\mathrm{O}_{\mathrm{PG}}} / 0.3$.

No PAD defined, but sector intensity disaggregated for $n$ subsectors, where $n$ is mining, steel, aluminium, primary metals, industrial chemicals, cement, pulp \& paper

No reliable PAD data are available for these industries (including general manufacturing and assembly, agriculture, construction, fishing and logging) so further decomposition analyses are not carried out here.

$\mathrm{PAD} \equiv$ floor area $\left(A_{\mathrm{CI}}\right)$ for $p$ subsectors where $p$ is wholesale, retail, warehouse, cultural, office, education, health, recreation, accommodation or other.

$\mathrm{PAD} \equiv$ tonne-km travelled (TKT) for $q$ types of vehicles where $q$ is heavy trucks, medium trucks, light trucks, air, rail or marine. of the calculations may be viewed in the Online resources.

The oil and gas (OG) sector analysis allows for the greatest level of disaggregation among all the sectors studied so it is described in more detail here to illustrate the method. Three subsectors are defined (extraction, pipelines, refineries), each of which has separately iden-

\begin{tabular}{|c|c|c|}
\hline Sectors & Equations & Factors, subsector and index definitions \\
\hline Residential (Res) & $\frac{E_{\mathrm{Res}}}{\text { capita }}=\frac{D}{\text { capita }} \sum_{r}\left(\frac{E_{\mathrm{Res}}}{A_{\mathrm{Res}}}\right)_{r}\left(\frac{A_{\mathrm{Res}}}{D}\right)_{r}\left(\frac{D_{r}}{D}\right)$ & $\begin{array}{l}\mathrm{PAD} \equiv \text { number of dwellings }(D) \text { and floor area }\left(A_{\mathrm{Res}}\right) \text { for } \mathrm{r} \text { types of residences where } \\
r \text { is single detached, single attached or apartments }\end{array}$ \\
\hline $\begin{array}{l}\text { Personal } \\
\text { Transportation } \\
\text { (PT) }\end{array}$ & $\frac{E_{\mathrm{PT}}}{\text { capita }}=\frac{\mathrm{PKT}}{\text { capita }} \sum_{s}\left(\frac{E}{\mathrm{PKT}}\right)_{s}\left(\frac{\mathrm{PKT}_{s}}{\mathrm{PKT}}\right)$ & $\begin{array}{l}\mathrm{PAD} \equiv \text { person kilometres of travel (PKT) for s vehicle types where } S \text { is walk, bike, } \\
\text { cars, light trucks, rail, air, intercity bus, mass transit or school bus. Note that values } \\
\text { for } E / \mathrm{PKT} \text { by vehicle type are derived by combining data for energy use by } \\
\text { vehicle type with data for PKT by vehicle type. }\end{array}$ \\
\hline
\end{tabular}
tified values for energy consumption, GDP and a PAD

Table 3 Household sectors (factorisation based on $E_{i} /$ capita) 
(see Table 2). For the extraction subsector $(j=$ ext), energy consumption and PAD data allow further disaggregation into three product categories: conventional oil, unconventional oil ${ }^{4}$ and natural gas. For the pipeline subsector $(j=\mathrm{pl})$, energy consumption and PAD data are available for two product categories: oil and gas. The refinery $(j=$ ref) subsector pertains only to oil.

The decomposition analysis then proceeds by applying the LMDI method to the equations in Table 2, first in isolating the impacts on sector $\Delta\left(E_{i} / \mathrm{GDP}_{i}\right)$ of changes in the structure of the industry (shares of sector GDP for each of the three subsectors - extraction, pipelines and refineries - $\left.\mathrm{GDP}_{j} / \mathrm{GDP}_{\mathrm{OG}}\right)$ vs. the impacts of changes in the energy intensities $\left(E_{j} / \mathrm{GDP}_{j}\right)$ of the subsectors. Then, changes in the subsector energy intensity $\left(E_{j} / \mathrm{GDP}_{j}\right)$ are factored into the separate impacts of changes in the physical energy intensity of the subsector $\left(E_{j} / \mathrm{PAD}_{j}\right)$ and changes in $\mathrm{PAD}_{j} / \mathrm{GDP}_{j}$ for the subsector. In the third and final stage (extraction and pipeline subsectors only), the physical energy intensity $\left(E_{j} / \mathrm{PAD}_{j}\right)$ is factored to separate the impact of changes in the mix of products from the impact of changes in the individual physical energy intensities for each product. The net result is a disaggregation of the impact of the changes in the sectoral energy intensity of the oil and gas sector into nine separate, additive components.

Similar but less-intensive decomposition analyses are carried out for the other business and household sectors as summarised in Tables 2 and 3.

In a final step, the results of the sector intensity decomposition analysis are nested within the results of the first order decomposition analysis to show the net contribution of structural and physical energy intensity (efficiency) impacts on total $\Delta(E / G D P)$.

Assessing variability in trends over the study period

The decomposition of total $\Delta(E / G D P)$ is carried out with data that covered the entire 15-year study period, 1995 to 2010 . However, to assess the sensitivity of the results to changes in the period studied, decomposition analyses are also carried out for an additional nine different

\footnotetext{
${ }^{4}$ Conventional oil refers to crude oil that is extracted using conventional oil well technology, and unconventional oil is that produced from other methods, usually from oil shale, tight formations or oil sands. In Canada, most unconventional oil production is from oil sands. The distinction is important in this analysis because oil sands extraction is much more energy intensive than conventional crude production, and its share of total production is growing.
}

study periods, each representing 12 to 14 years. For each study period, total $\Delta(E / G D P)$ values are expressed per year, and then all ten study periods are averaged to calculate the mean, standard error ( $\mathrm{SE}=$ standard deviation $\left./ \sqrt{ }_{n}\right)$ and the SE as a per cent of the mean (\%SE) for each parameter for all ten study periods. In presenting the results, a triple asterisk (***) is used to indicate a $\%$ SE value of $\leq 5 \%$, a double asterisk $(* *)$ denotes a $\%$ SE of $\leq 10 \%$ and a single asterisk, a $\%$ SE of $\leq 15 \%$. No asterisk denotes a $\%$ SE of $>15 \%$.

\section{Results and discussion}

The sector-by-sector decomposition analyses of the business and household sectors reveal both energy efficiency and a diversity of intrasector structural factors affect changes in sector energy intensities and their corresponding impacts on total $\Delta(E / \mathrm{GDP})$.

Oil and gas industry

The Oil and Gas industry is the only business sector in our first order analysis that exhibits a net positive impact on the total change in energy intensity $(\Delta(E / \mathrm{GDP}))$ of the Canadian economy, totalling $+0.40 \mathrm{MJ} / \$$ over the 1995 to 2010 period (Fig. 2c). This represents a significant offset of the impact of all the other business sectors that collectively had net negative impact of $-0.98 \mathrm{MJ} / \$$ on the total change in energy intensity.

The observed positive impact on total $\Delta$ (E/GDP) from the Oil and Gas sector is almost entirely due to an increase in the subsector energy intensities $\left(\Delta\left(E_{i} / \mathrm{GDP}_{i}\right)\right)$ rather than any shift in the relative shares of each subsector to the GDP of the Oil and Gas sector (Fig. 3a). Indeed, the extraction subsector accounts for over $85 \%$ of the GDP produced by the oil and gas industry, and this share did not change much over the 1995-2010 period.

Subsequent decomposition of the total $\Delta(E / G D P)$ impacts from subsectors reveals that oil and gas extraction contributed $+0.59 \mathrm{MJ} / \$$ over the period, while the pipeline and oil refinery subsectors contributed $-0.13 \mathrm{MJ} / \$$ and $-0.07 \mathrm{MJ} / \$$, respectively, thereby partly offsetting the impact of oil and gas extraction (Fig. 3b).

The large positive impact of the extraction subsector on total $\Delta(E / \mathrm{GDP})$ is not due to an increase in product value $\left(\Delta\left(\mathrm{Eo}_{\mathrm{ext}} / \mathrm{GDP}_{\mathrm{ext}}\right)\right.$, Fig. 3c), but to two other factors. First, there was a shift in the mix of oil and gas production $(+0.48 \mathrm{MJ} / \$$, Fig. 3d) from conventional to 


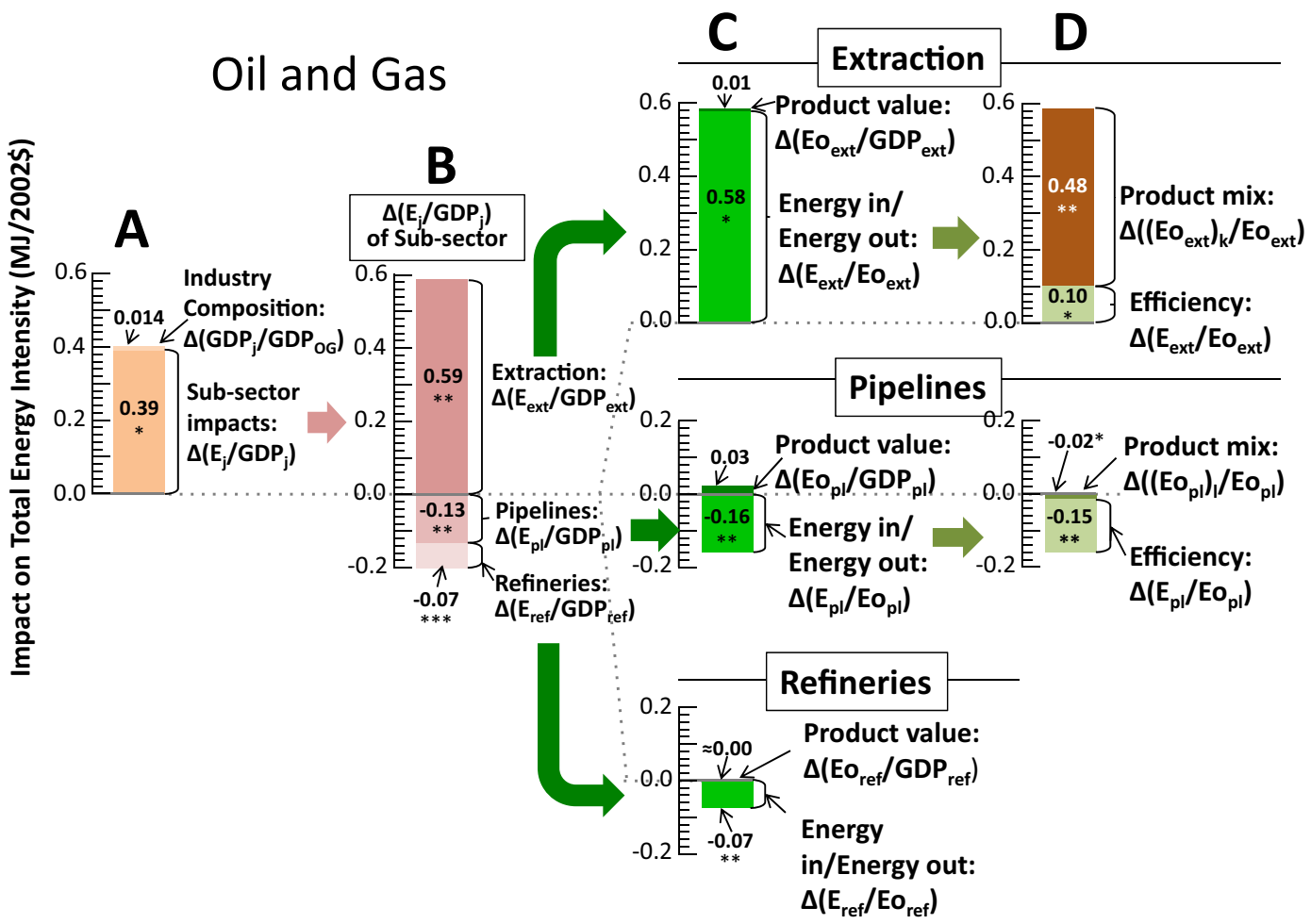

Fig. 3 Decomposition of the impact of the oil and gas (OG) sector on the $\Delta(E / G D P)$ of the Canadian economy between 1995 and 2010 . Charts a to $d$ represent the sequential decomposition of the total impact of the OG sector presented in Fig. 2c. See Table 2 for equations

unconventional oil, especially to bitumen extraction by Steam Assisted Gravity Drainage (SAGD) that is more energy intense than other forms of oil production (Bergerson et al. 2012). Second, the energy needed to deliver each unit of production increased $(+0.10 \mathrm{MJ} / \$$, Fig. 3d), especially for the production of conventional oil.

For the pipeline and refinery subsectors, the negative contributions to total $\Delta(E / G D P)$ are almost wholly attributable to significant declines in the energy needed for each unit of product delivered via pipeline $\left(\Delta\left(E_{\mathrm{pl}} / \mathrm{Eo}_{\mathrm{pl}}\right)\right.$, Fig. 3d) or processed in a refinery $\left(\Delta\left(E_{\mathrm{ref}} / \mathrm{Eo}_{\mathrm{ref}}\right)\right.$, Fig. 3c).

In summary, the Oil and Gas industry as defined for this analysis contributed $+0.40 \mathrm{MJ} / \$$ to the total $\Delta(E /$ GDP) over the 1995-2010 period, an increase attributable mainly to the shift to oil sands extraction. The total impact would have been as high as $+0.59 \mathrm{MJ} / \$$ if not for the offsetting effects of enhanced efficiency and lowered energy intensity in the pipeline and oil refinery segments.

\section{Power generation}

The power generation industry contributed $-0.14 \mathrm{MJ} / \$$ to the total $\Delta(E / \mathrm{GDP})$ of the Canadian economy over the study period (Fig. 2c). Decomposition of this result shows that $-0.08 \mathrm{MJ} / \$$ results from reduction of the energy input need to generate each unit of electricity for the grid (Fig. 4a), and $-0.06 \mathrm{MJ} / \mathrm{\$}$ is due to a shift in the generation mix (Fig. 4b). During the 1995-2010 period, absolute production and relative shares of both coal and nuclear generation declined while the absolute output and share of more efficient natural gas generation increased.

The average carbon intensity of electricity generated in Canada in 2010 was a moderate $200 \mathrm{~g} / \mathrm{kWh}$, but each province has an independent grid and the carbon intensity of electricity varies from as little as $2-20 \mathrm{~g} / \mathrm{kWh}$ in the hydro-rich provinces (Quebec, Manitoba, Newfoundland and British Columbia) to $800-900 \mathrm{~g} / \mathrm{kWh}$ in provinces reliant primarily on fossil generators (Alberta, Saskatchewan, Nova Scotia). In 2010, the carbon intensity of the mixed grid in Ontario (the most populous province) was $150 \mathrm{~g} / \mathrm{kWh}$ with a mix of nuclear $(58 \%)$, hydro (23\%), fossil (18\%) and wind (1\%), and the phasing out of all coal-fired power has since reduced the carbon intensity of Ontario electricity to $40 \mathrm{~g} / \mathrm{kWh}$. A provincially disaggregated version of this analysis would shed further light on the energy intensity trends in Canada's power industry. 
Fig. 4 Decomposition of the impact of the power generation (PG) sector on the $\Delta(E / G D P)$ of the Canadian economy between 1995 and 2010. Charts a and b represent the sequential decomposition of the total impact of PG sector presented in Fig. 2c. See

Table 2 for equations

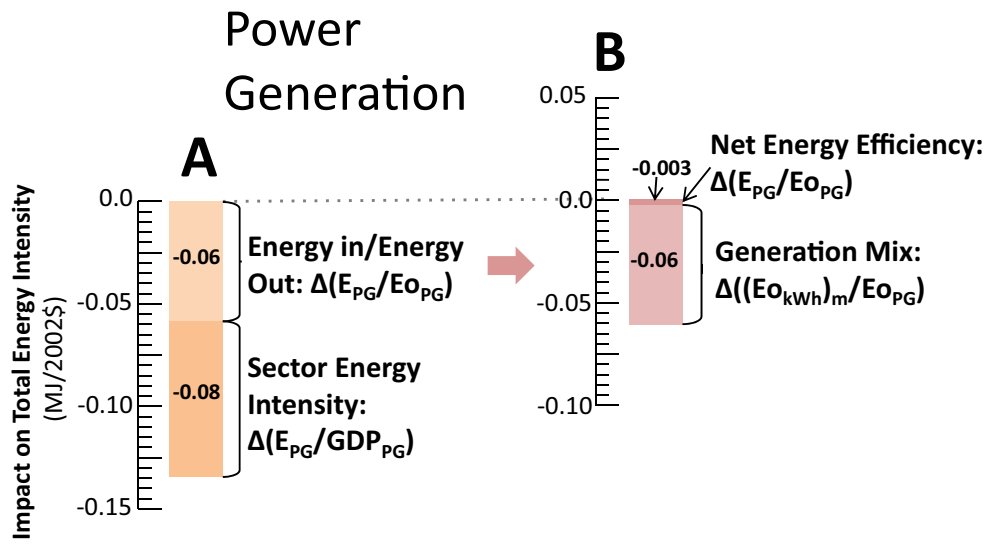

Energy intensive industries

The energy intensities of the five industries in this sector range from $30 \mathrm{MJ} / \$$ (mining) to $68 \mathrm{MJ} / \$$ (cement) in 2010 , several times higher than the overall energy intensity of the Canadian economy $(8.6 \mathrm{MJ} / \$)$ and as much as 20-50 times higher than the energy intensities that prevail in the general manufacturing or in the commercial sectors of the economy (Torrie et al. 2016). As a sector, energy intensity of these industries declined over the 1995-2010 period, sufficient to contribute $-0.19 \mathrm{MJ} / \$$ to the total $\Delta$ (E/GDP) (Fig. $2 \mathrm{c}$ ).

Decomposition analysis shows little change in each industry's share of the combined GDP of the energy intensive sector and that the sector's energy intensity decline stemmed almost entirely from declines in the subsector energy intensities (Fig. 5a). The GDP for this sector peaked in 2005 and declined from 2005 to 2010 for all subsectors, with the result that sector GDP in 2010 was about the same level it was in 1995. In 2010, subsector energy intensities were below 1995 levels for all these energy intensive industries, except mining (Fig. 5b).

The increase in the mining industry's energy intensity occurred between 2005 and 2010 during which time its GDP fell by $11 \%$ while energy consumption continued to grow. This trend in the mining industry underscores the variability of energy intensity in energy intensive industries where changes in commodity prices, economic conditions, capacity utilisation and raw material quality could all contribute to a change in sector $E /$ GDP. The data for these industries reflects this variability over the 1995-2010 period. Physical production data to support further decomposition of energy intensity trends is only available for some industries so we are unable to generate a dataset of mutually consistent GDP and physical output data to support further decomposition of each subsector.

Overall, the results point to reduced fuel and electricity use per GDP generated over the 1995-2010 period. This could be associated with a shift toward higher value products like coated papers and specialty steels that require less energy per dollar of value added than lower value products such as pulp and raw steel. The energy consumption patterns of these industries have been the subject of other decomposition analyses (Ang and Xu 2013; Nanduri et al. 2002; NRCan 2016).

Manufacturing and other industries

In 2010, the other industry sector generated $19 \%$ of Canada's GDP (down from $22 \%$ in 1995) with an average sectoral energy intensity of $3.4 \mathrm{MJ} / \$$, down from $4.5 \mathrm{MJ} / \$$ in 1995 . The decline in the energy intensity of this sector contributed $-0.24 \mathrm{MJ} / \$$ to the total $\Delta E / \mathrm{GDP}$ of the Canadian economy, as illustrated in Fig. 2c. This energy intensity drop is likely due to energy efficiency improvements, but data are not available for the identification and quantification of physical activity drivers in this diverse sector so we do not attempt a decomposition analysis of sector energy intensity.

\section{Commercial and institutional}

The service sector takes place primarily in commercial and institutional buildings and constitutes, by far, the largest sector of the business economy in this analysis, 
Fig. 5 Decomposition of the impact of the energy intensive industry (EII) sector on the $\Delta(E /$ GDP) of the Canadian economy between 1995 and 2010. Charts a and $\mathrm{b}$ represent the sequential decomposition of the total impact of EII sector presented in Fig. 2c. See Table 2 for equations

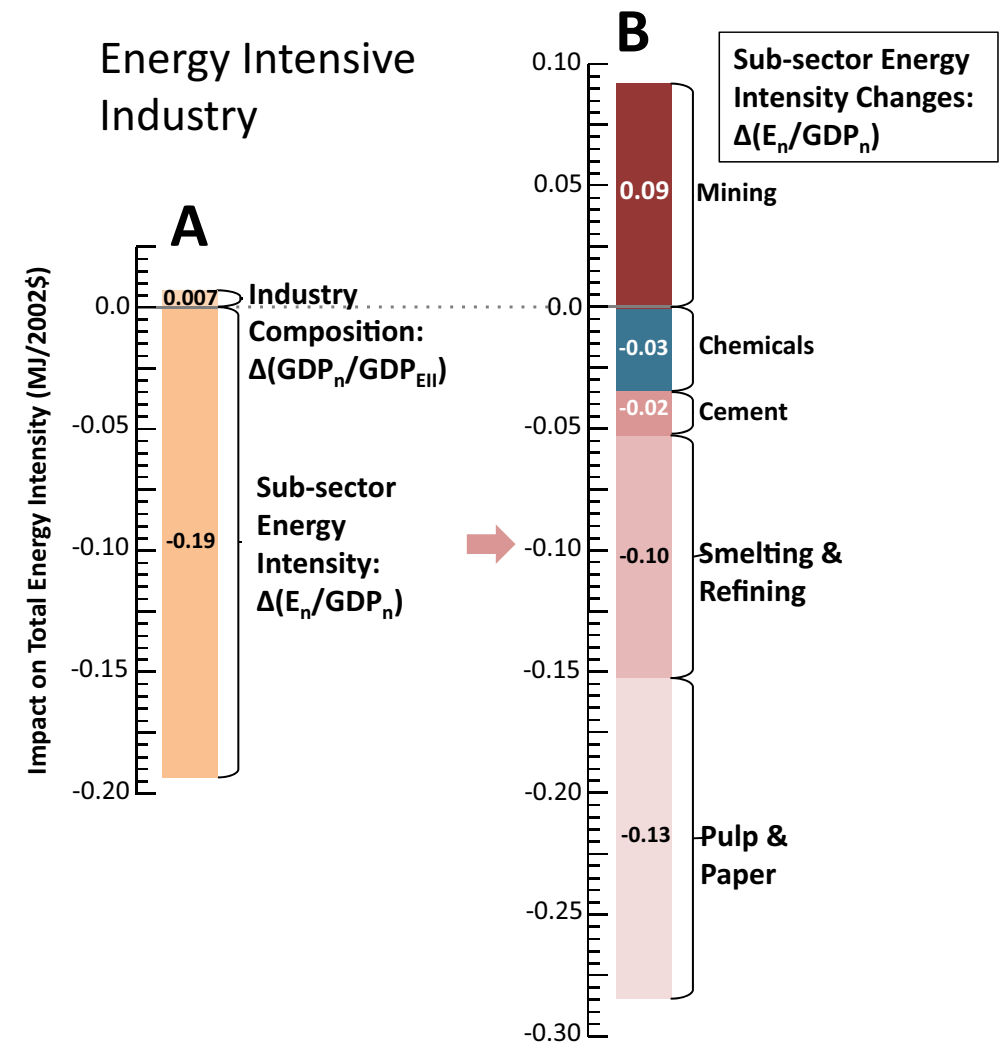

comprising 68\% of GDP in 2010, up from 62\% in 1995. 2010 , translating into a $-0.24 \mathrm{MJ} / \$$ impact on the total $\Delta(E / G D P)$ (Fig. 6a).

It also has the lowest energy intensity at $1.25 \mathrm{MJ} / \$$ (down from $1.85 \mathrm{MJ} / \$$ in 1995). Its large share of GDP magnifies the impact on total $\Delta(E / G D P)$ of even relatively small changes in sector energy intensity. As a result, the commercial and institutional sector, at $-0.41 \mathrm{MJ} / \$$, was the single largest contributor to the total $\Delta(E / \mathrm{GDP})$ over the 1995-2010 period (Fig. 2c). Decomposition of the underlying data shows it to be the sum of $-0.24 \mathrm{MJ} / \$$ from a decline in floor area per dollar of sector GDP (i.e. more GDP is being generated per square metre of building floor area in 2010 than in 1995) and $-0.17 \mathrm{MJ} / \$$ from a decline in the energy use per square metre of floor area throughout the sector (Fig. 6a).

Some activities in this sector are tied less to economic growth than to population growth-for example, education (school buildings) - resulting in floor space requirements growing slower than GDP. In other areas, business trends, office technology and other innovations exhibit slower growth of floor space as compared with economic value creation. Sectorwide average floor area per dollar of GDP in Canada declined $20 \%$ from $1.06 \mathrm{~m}^{2} / \$$ in 1995 to $0.85 \mathrm{~m}^{2} / \$$ in
Freight transportation

Over the 1995 to 2010 period, the net impact on total $\Delta(E / G D P)$ of changes in the energy intensity of freight transportation was only $-0.01 \mathrm{MJ} / \$$, the smallest impact of all the business economy sectors (Fig. 2c). However, decomposition of the $\Delta$ (E/GDP) contribution shows it to be the result of countervailing impacts of changes in transport productivity $(-0.07 \mathrm{MJ} / \$)$ and transport efficiency $(+0.06 \mathrm{MJ} / \$)$ (Fig. 7a), where the transport efficiency is itself the result of countervailing impacts of changes in mode share $(+0.20 \mathrm{MJ} / \$$, in particular from relatively more truck and less rail) and vehicle efficiency within each mode $(-0.14 \mathrm{MJ} / \$)$ (Fig. $7 \mathrm{~b})$. The improvements in vehicle efficiency that impact the total $\Delta(E / G D P)$ may be associated with technology improvements, driver behaviour or greater capacity utilisation (particularly for trucks and light commercial vehicles). 
Fig. 6 Decomposition of the impact of the commercial and institutional (CI) sector on the $\Delta(E / G D P)$ of the Canadian economy between 1995 and 2010. Charts $\mathrm{a}$ and $\mathrm{b}$ represent the sequential decomposition of the total impact of CI sector presented in Fig. 2c. See Table 2 for equations

\section{Commercial \& Institutional}

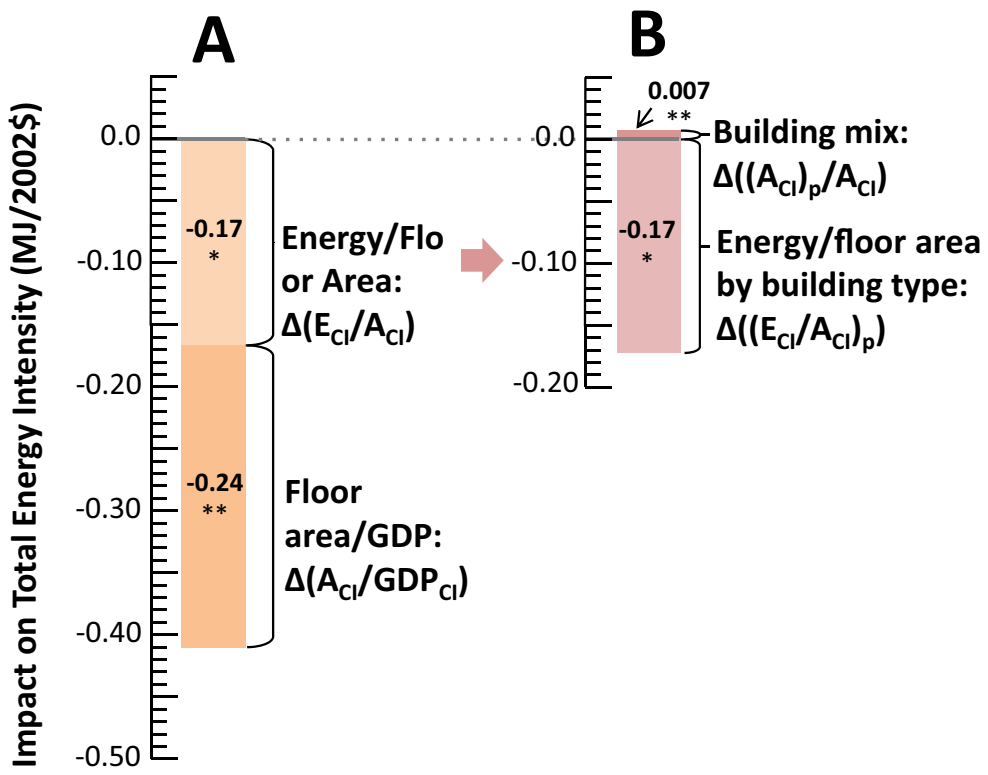

\section{Residential}

Between 1995 and 2010, residential energy intensity declined by $16 \%$ from 46 to $39 \mathrm{GJ} /$ capita, contributing $-0.20 \mathrm{MJ} / \$$ to total $\Delta(E / \mathrm{GDP})$, as shown in Fig. $2 \mathrm{c}$. Decomposition of this change reveals that the decline would have been larger if not for the trends over the period toward fewer persons per dwelling (contributing $+0.06 \mathrm{MJ} / \$$, Fig. 8a) and toward larger dwellings (contributing $+0.07 \mathrm{MJ} / \$$ ).

Between 1995 and 2010, the average dwelling occupancy rate in Canada declined from 2.5 to 2.4 persons/ dwelling, and this increased the per capita residential energy use because the increased dwelling space had to be heated/cooled, lighted and equipped with appliances. Averaged across all dwelling types, energy use declined $20 \%$ over the study period, from 117 to $93 \mathrm{GJ} / \mathrm{dwelling}$, primarily due to a $25 \%$ drop in energy use per square metre of residential floor area, which contributed $-0.34 \mathrm{MJ} / \$$ to the total $\Delta(E / \mathrm{GDP})$ of the Canadian economy over the 1995-2010 period (Fig. 8b), putting it on a par with the decline in commercial building energy intensity and comparable with the upward pressure on total $\Delta(E / \mathrm{GDP})$ from the oil and gas industry of $+0.40 \mathrm{MJ} / \$$. The effect was partially offset by a $6 \%$ increase in average dwelling size which contributed $+0.07 \mathrm{MJ} / \$$ to total $\Delta E / \mathrm{GDP}$, reducing the net impact of the decline in per household energy use on total $\Delta E /$ GDP to $0.26 \mathrm{MJ} / \$$ (Fig. 8a).

\section{Personal transportation}

Per capita energy use for personal transportation was similar in 1995 and 2010, so it had only a small, impact of $+0.04 \mathrm{MJ} / \$$ on the total $\Delta(E / G D P$ ) (Fig. 2c). However, decomposition analysis reveals that this result was the net impact of larger, countervailing influences (Fig. 9). Over the 1995-2010 period, per capita mobility increased by $14 \%$ or 2500 PKT/capita, causing an increase in personal transportation energy intensity of $5.6 \mathrm{GJ} /$ capita, which translates into a $+0.15-\mathrm{MJ} / \$$ contribution to total $\Delta(E / \mathrm{GDP})$ (Fig. 9a). This was offset by a 9\% reduction in energy use per PKT that translates to a $-0.12 \mathrm{MJ} / \$$ contribution in the total $\Delta(E / \mathrm{GDP})$ over the study period (Fig. 9a).

A second-stage factorisation of the decline in energy/PKT reveals that it too resulted from offsetting factors. Reduced energy consumption per PKT, due primarily to a $7.5 \%$ improvement vehicle fuel efficiency over the period, contributed $-0.18 \mathrm{MJ} / \$$ to the total $\Delta(E / \mathrm{GDP})$, but was partially offset by a +0.07 $\mathrm{MJ} / \$$ contribution from the trend toward SUVs and light trucks (Fig. 9b). 
Fig. 7 Decomposition of the impact of the freight transport (FT) sector on the $\Delta(E / \mathrm{GDP})$ of the Canadian economy between 1995 and 2010. Charts a and b represent the sequential decomposition of the total impact of the FT sector presented in Fig. 2c. See Table 2 for equations

\section{Freight Transport}

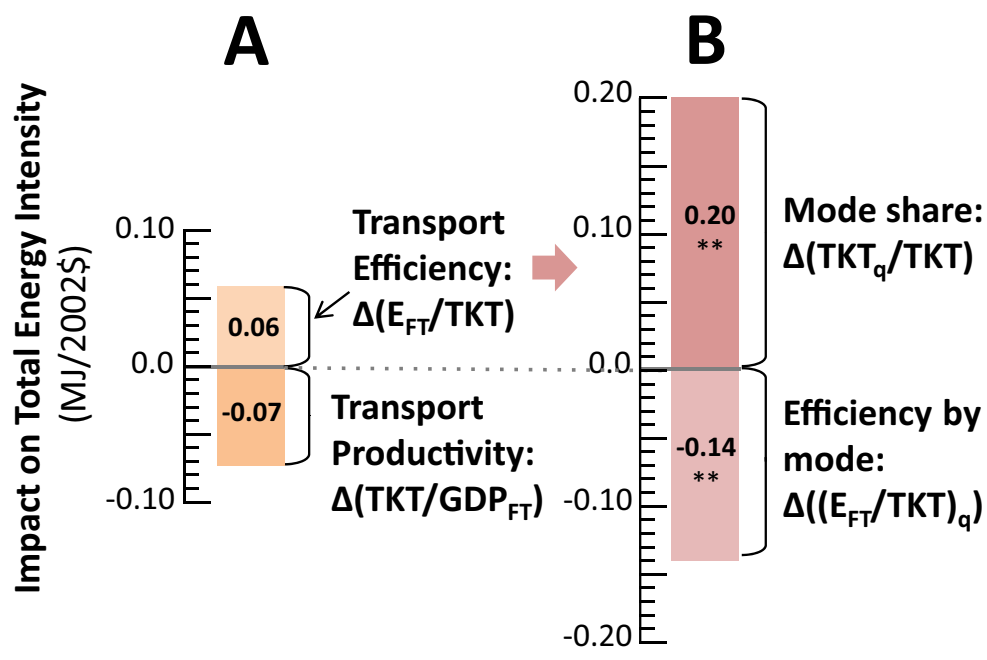

Compilation of all sector intensity decomposition results

Figure 10 provides a compilation of all sector intensity factors studied here, arranged to show their contribution (positive to negative) to total $\Delta(E / G D P)$. Only those factors that are additive are included, so that the sum of all the factors equals $-0.75 \mathrm{MJ} / \$$, reflecting the contributions from business sector intensity changes $(-0.58 \mathrm{MJ} / \$)$ and from per capita energy intensity changes in the household sectors $(-0.17 \mathrm{MJ} / \$)$, as illustrated in Fig. $2 b$.

The red bars in Fig. 10 represent physical energy intensity (energy efficiency) impacts $\left(\Delta\left(E_{i} / \mathrm{PAD}_{i}\right)\right)$, the blue bars represent the 'intrasectoral structural factors' that affect the internal composition of the sector (e.g. housing mix, vehicle mix) or the PAD/GDP relationship for the sector (e.g. CI floor area per GDP, PKT per capita) and the grey bars represent the impact on $\Delta(E /$
Fig. 8 Decomposition of the impact of the residential (Res) sector on the $\Delta(E / G D P)$ of the Canadian economy between 1995 and 2010. Charts a and b represent the sequential decomposition of the total impact of the Res sector presented in Fig. 2c. See Table 3 for equations

\section{Residential}

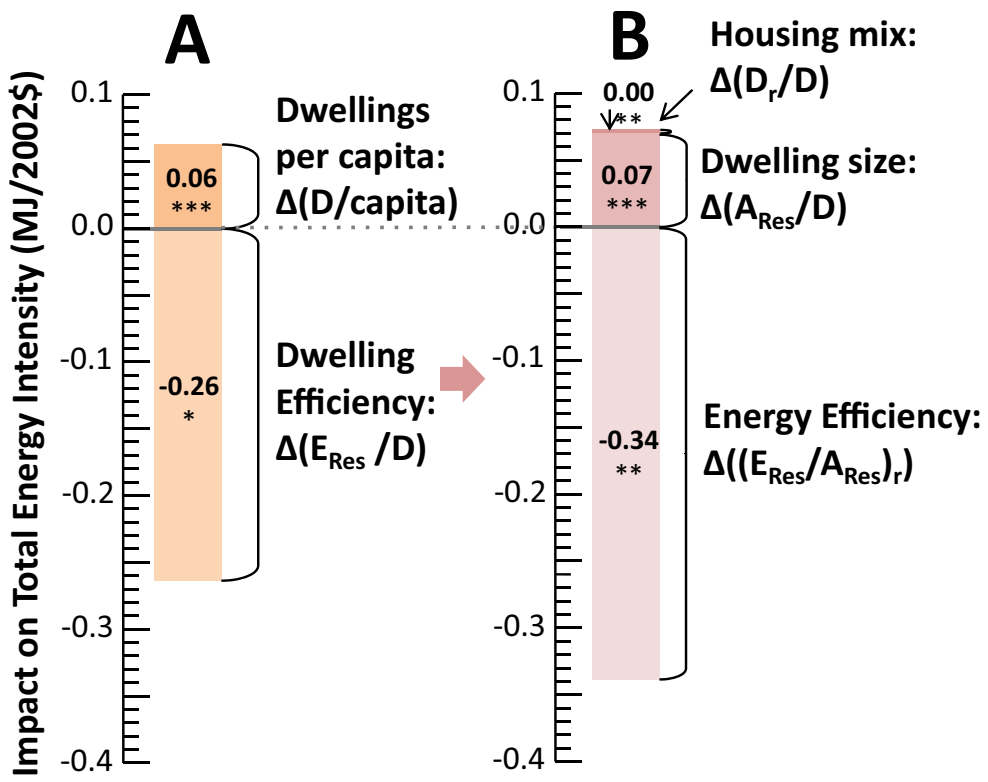


Fig. 9 Decomposition of the impact of the personal transport (PT) sector on the $\Delta(E / G D P)$ of the Canadian economy between 1995 and 2010. Charts A and B represent the sequential decomposition of the total impact of the PT sector presented in Fig. 2c. See Table 3 for equations

\section{Personal Transport}

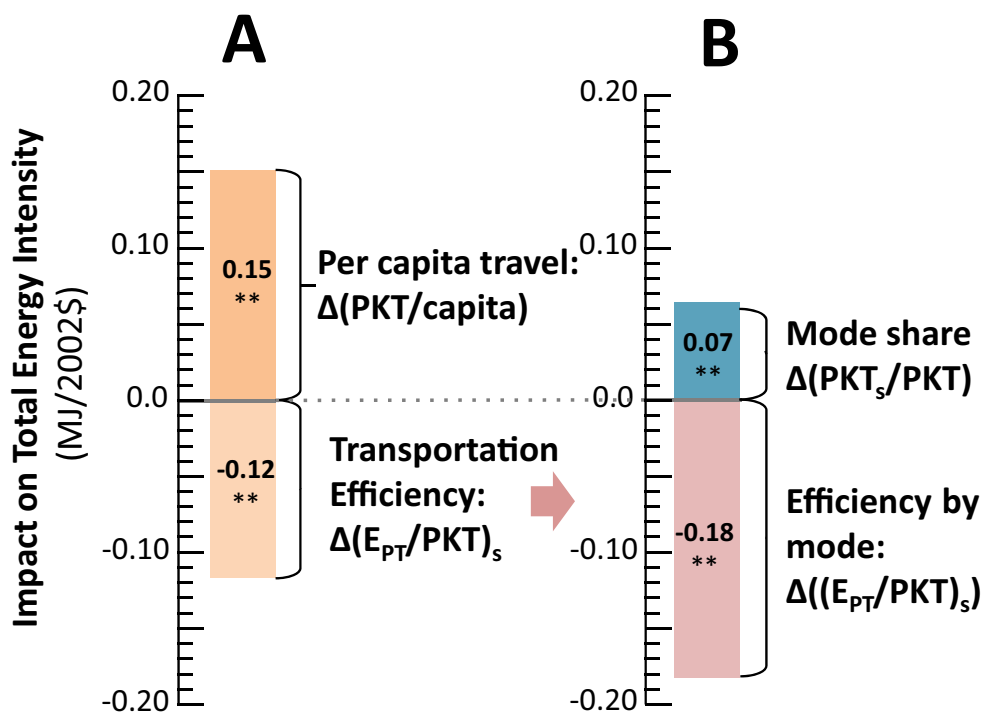

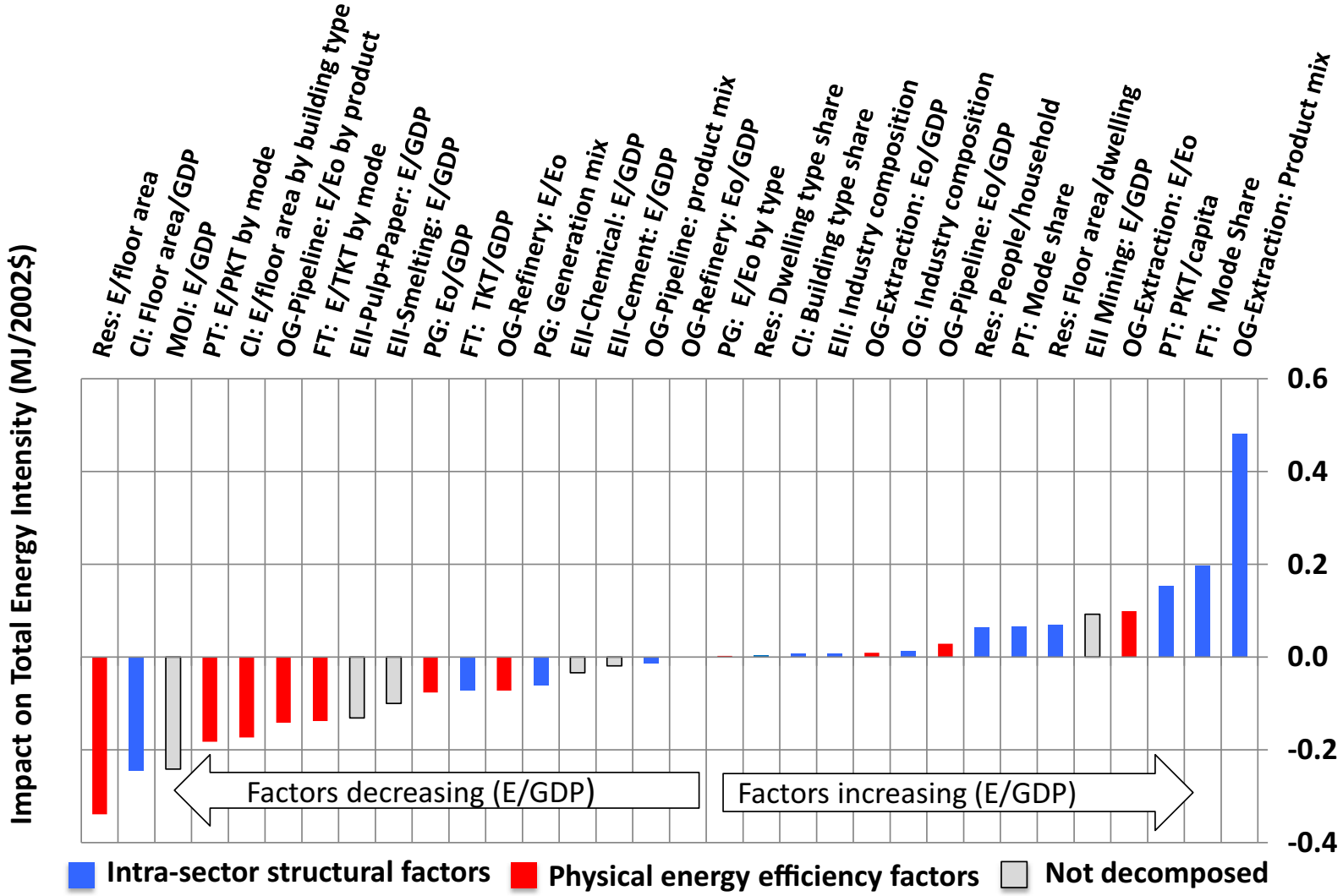

Fig. 10 A compilation of the most highly deconstructed factors from Figs. 3, 4, 5, 6, 7, 8 and 9, are arranged in order of their impact on the total $\Delta(E / G D P)$ of the Canadian economy. Factors have been classified into physical energy intensity impacts (red bars), 'intrasector structural factors (blue bars) and unclassified (grey bars). See text for details 
GDP) of energy intensity changes in the two sectors that were not subject to further decomposition analysis (energy intensive industries, manufacturing and other industry).

The intrasector structural factors (blue) are more common among those factors that made an upward contribution to total $\Delta(E / G D P)$ whereas the energy intensity factors (red and grey) are more common among factors that made a downward contribution to total $\Delta(E /$ GDP). The 'blue factors' account for $82 \%$ of the $1.3 \mathrm{MJ} /$ $\$$ upward pressure on total $\Delta(E / \mathrm{GDP})$, whereas the 'red and grey factors' account for $79 \%$ of the $2.0 \mathrm{MJ} / \$$ downward pressure on total $\Delta(E / G D P)$.

The factors 'above the line' in Fig. 10 add up to a $1.3 \mathrm{MJ} / \$$ increase in total $\Delta(E / \mathrm{GDP})$, of which $49 \%$ is associated with the oil and gas industry, which in turn is due primarily to the shift to oil sands extraction (product mix), but also to the increase in the energy intensity of conventional oil extraction. Other significant contributions to the positive pressure on total $\Delta(E / G D P)$ include the modal shift from rail to truck in the freight transportation sector, increased personal mobility and the trend toward larger houses and bigger cars (Fig. 10).

On the other side of the ledger, the factors 'below the line' in Fig. 10 add up to a $2.0 \mathrm{MJ} / \$$ decrease in total $\Delta(E / \mathrm{GDP}), 58 \%$ of which is due to three factors: (a) reductions in the physical energy intensities of housing, commercial buildings, and personal vehicles; (b) the overall reduction in the energy/GDP ratio of the 'other industry' sector and (c) the reduction in the amount of floor area per dollar of value added in the CI sector.

The lower-energy intensity of residential and commercial buildings contributed $-0.51 \mathrm{MJ} / \$$ to the total $\Delta(E / \mathrm{GDP})$, more than offsetting the impact of the increase in bitumen's share of production in the oil and gas industry. The decline in energy use per floor area for the residential and commercial building sectors was a result of increasing energy service intensity (an intrasector structural factor) and reductions in the energy required per unit of energy service delivered (an energy efficiency factor). When structural factors work in the same direction as energy efficiency factors, the benefits can be substantive.

For the energy-intensive and other industries (grey bars, Fig. 10), further decomposition analyses would likely reveal additional intrasector structural factors in addition to changes in energy efficiency.

This analysis shows the extent to which the sector energy intensity impacts obtained with first-order decomposition analysis are themselves composed of structural and efficiency (physical intensity) factors. Intrasectoral structural changes make significant contributions to changes in sector energy intensities and can be positive or negative. For example, the observed energy intensity decline in the commercial sector is twice as large as it would be if due to physical energy intensity alone; reduced energy use per square metre of floor area was matched by a decline in floor area per dollar of GDP from the sector. A contrasting example is provided by the freight transportation sector where improvements in vehicle fuel efficiency were completely offset by an increase in tonne-km per GDP, resulting in almost no net impact from sector energy intensity.

In aggregate, the business and household energy intensity impact on $\Delta(E / G D P)$ of $-0.75 \mathrm{MJ} / \$$ was the result of $-1.41 \mathrm{MJ} / \$(-0.98 \mathrm{MJ} / \$$ from energy efficiency and $-0.43 \mathrm{MJ} / \$$ that could not be confidently disaggregated into efficiency or structural impacts), offset by $0.67 \mathrm{MJ} / \$$ increase from intrasectoral activity and structure changes.

The bigger picture

In Fig. 11, we combine the results in Fig. 10 with those from Fig. 2 to show the net contributions to total $\Delta(E /$ GDP) from energy efficiency (physical intensity) vs. both intersector and intrasectoral structural changes in the Canadian economy. As shown in Fig. 11a, 72\% of the $2.64 \mathrm{MJ} / \$$ decline in the Canadian $E / G D P$ was due to structural factors that included both intersector structural and GDP/capita impacts. The remaining $28 \%(-0.75 \mathrm{MJ} / \$)$ decline in total $\Delta(E / \mathrm{GDP})$ is associated with sector energy intensity impacts, but as shown in Fig. 10, many of these impacts were also structural (intrasector structure), contributing $+0.67 \mathrm{MJ} / \$$ to total $\Delta(E / G D P)$ (Fig. $11 \mathrm{~b}$ ). The physical energy intensity or energy efficiency contribution to $\Delta(E / G D P)$ was $-0.98 \mathrm{MJ} / \$$, larger than the net impact of sector intensity change. Consequently, the net impact of structural factors was $46 \%(-1.22 \mathrm{MJ} / \$)$ of the total $\Delta(E / G D P)$ in the Canadian economy while an additional $37 \%(-0.98 \mathrm{MJ} / \$)$ was associated with the energy efficiency improvements. The remaining $16 \%(-0.43 \mathrm{MJ} / \$)$ is not decomposed in this analysis (Fig. 11c).

The impact of energy efficiency on total $\Delta(E / G D P)$ is masked by the intrasectoral structural impacts which, for the sectors analysed, exerted upward pressure on $\Delta(E /$ GDP), in contrast with the larger intersectoral structural 


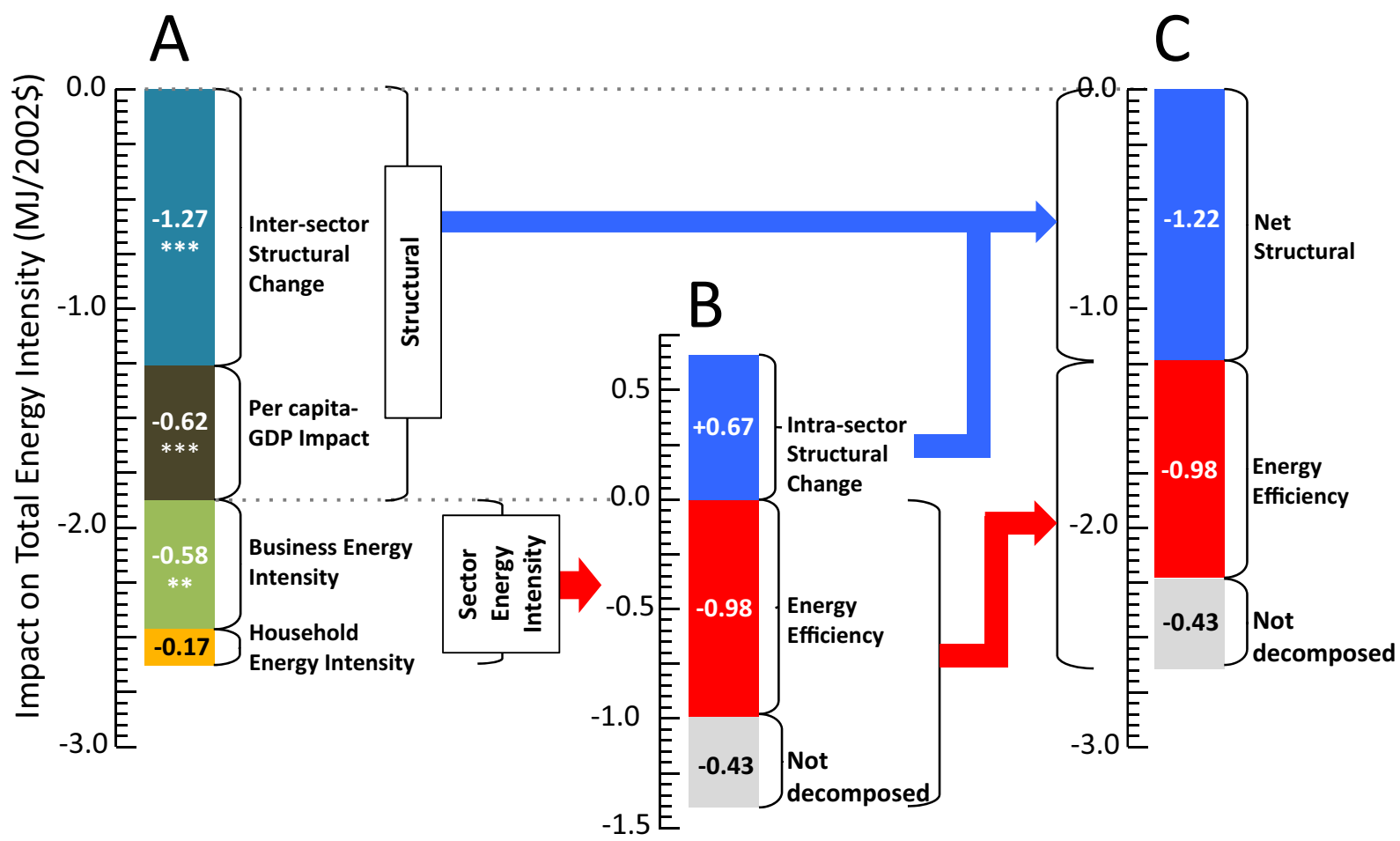

Fig. 11 Structural vs. sector energy intensity impacts on total $\Delta(E /$ GDP) of the Canadian economy between 1995 and 2010 (a). The sector energy intensity impacts from Fig. 10 were separated into intrastructural impacts, energy efficiency impacts and not

decomposed (b). When the intrastructural impacts were added to the other structural impacts, the total $\Delta(E / G D P)$ of the Canadian Economy was decomposed to show the net structural impacts (c)

and GDP/capita impacts, which were strongly negative over the 1995-2010 period.

\section{Conclusions and policy implications}

As efforts intensify to identify pathways for deep decarbonisation of industrial and post-industrial economies, there is increasing interest in understanding the dynamics of primary energy intensity (E/GDP). Sectorlevel decomposition analysis that is mathematically integrated with intersectoral analysis reveals the contributions of energy efficiency at both the sector and economy-wide levels and provides the missing link between physical metrics of energy efficiency and the $E / G D P$ indicator. It provides a versatile tool for assessing the contribution of energy efficiency programs to sector energy intensities, for placing energy efficiency policies in the larger context of the other factors that determine an economy's energy intensity, for identifying non-efficiency policy targets for improving energy productivity, and for increasing the sophistication of

forecasting and scenario analysis of future levels and patterns of fuel and electricity consumption.

- With regard to the energy intensity of individual sectors of the economy, the results presented here for the case of Canada from 1995 to 2010 illustrate the extent to which non-energy efficiency factors can distort and even completely obscure the impacts of energy efficiency on sector energy intensities. These intrastructural factors can augment or offset energy efficiency, and the method illustrated here has direct applications in energy efficiency policy development and evaluation.

- At the level of the economy, the decomposition of sector energy intensity into efficiency and intrasectoral structural effects, and the integration of that analysis into the economy-wide decomposition analysis, allows the quantification of the contribution of energy efficiency to changes in E/GDP. This increases the practical utility of decomposition analysis by reconciling energy efficiency metrics with the $E /$ GDP indicator. For example, in the Canadian case 
used to illustrate the method here, a first order decomposition analysis attributes $28 \%$ of the drop in $E /$ GDP from 1995 to 2010 to decreased sector energy intensities. However, the sector decomposition analyses reveal the contribution of energy efficiency to $\Delta(E / \mathrm{GDP})$ over this period was at least $37 \%$, before the offsetting effect of intrasectoral structural factors.

- While the focus in this research has been on the quantitative integration of energy efficiency in decomposition analysis of changes in E/GDP, by corollary, it also improves understanding and disaggregation of non-efficiency factors that influence primary energy intensity. To the extent that climate change response policies are expanding beyond energy efficiency and carbon intensity to consider other technological and system changes that can accelerate the transition to low carbon futures, the identification and quantification of intrasectoral structural contributions to lower $E / \mathrm{GDP}$ will be useful.

- With regard to the application of this research to foresight analysis, decomposition analysis of $\Delta(E)$ GDP) at the sector level provides insights that can be used in the construction of the energy and emission projections embodied in both the baselines and future scenarios used for energy and climate change policy analysis (Shahiduzzaman and Layton 2017). Separately identifying and quantifying efficiency vs. structural impacts on per capita and per GDP energy intensities at the sector and subsector level allows the modeller to also represent these factors separately in projections and scenarios of future energy use and related emissions.

- These results are for the national economy, but the method can be applied in any context where compatible energy, GDP and PAD data are available, including for cities, provinces, states and regions. In the case of Canada, there are significant regional variations in makeup and dynamics of the E/GDP relationship. Most notably, of all the intrasector structural factors that affect the $\Delta(E / G D P)$ over the 1995-2010 period, the largest is the growth in bitumen's share of crude oil production. This occurred only in Alberta, and decomposition of $\Delta(E / G D P)$ for individual provinces other than Alberta would therefore be expected to show a relatively larger contribution to sector energy intensity changes from energy efficiency than from intrasectoral structural factors. In Canada, most aspects of energy policy are the domain of provincial governments, and the application of this type of analysis at the provincial level would yield policy insights that may be obscured by the national results presented here.

The application of decomposition analysis at the sector and subsector level provides researchers and policy makers with a valuable tool for reconciling energy intensity and energy efficiency metrics and for better understanding and influencing the dynamics of total $\Delta(E / G D P)$ and related greenhouse gas emissions. By nesting such sectoral analyses in the same data and computational framework used for higher order and intersectoral decomposition analysis we gain the added advantage of being able to place the intrasectoral factors in their larger context. Further refinements and extensions of this approach are recommended to support the broad scope of emission reduction strategies that will be necessary to respond to the challenge of achieving low carbon economies.

Acknowledgements The authors wish to thank whatIf? Technologies Inc. for their generous donation of the calibrated national data on the energy systems of Canada.

Funding information This work was funded through grants from the University of Calgary and from the Edmonton Community Foundation. The funding sources had no involvement in the study design; in the collection, analysis and interpretation of data; in the writing of the report; or in the decision to submit the article for publication.

\section{Compliance with ethical standards}

Conflict of interest The authors declare that they have no conflict of interest.

Open Access This article is distributed under the terms of the Creative Commons Attribution 4.0 International License (http:// creativecommons.org/licenses/by/4.0/), which permits unrestricted use, distribution, and reproduction in any medium, provided you give appropriate credit to the original author(s) and the source, provide a link to the Creative Commons license, and indicate if changes were made.

\section{References}

Andreoni, V., \& Galmarini, S. (2016). Drivers in $\mathrm{CO}_{2}$ emissions variation: a decomposition analysis for 33 world countries. Energy, 103, 27-37.

Ang, B. W. (2004). Decomposition analysis for policymaking in energy: which is the preferred method? Energy Policy, 32, 1131-1139. 
Ang, B. W. (2015). LMDI decomposition approach: a guide for implementation. Energy Policy, 86, 233-238. https://doi. org/10.1016/j.enpol.2015.07.007.

Ang, B. W., \& Liu, F. L. (2001). A new energy decomposition method: perfect in decomposition and consistent in aggregation. Energy, 26, 537-547.

Ang, B. W., \& Wang, H. (2015). Index decomposition analysis with multidimensional and multilevel energy data. Energy Economics, 51, 67-76.

Ang, B. W., \& Xu, X. Y. (2013). Tracking industrial energy efficiency trends using index decomposition analysis. Energy Economics, 40, 1014-1021.

Ang, B. W., Mu, A. R., \& Zhou, P. (2010). Accounting frameworks for tracking energy efficiency trends. Energy Economics, 32, 1209-1219.

Bashmakov, I., \& Myshak, A. (2014). Russian energy efficiency accounting system. Energy Efficiency, 7, 743-759. https://doi.org/10.1007/s12053-014-9252-z.

Bataille, C., Rivers, N., Mau, P., Joseph, C., \& Tu, J. (2007). How malleable are the greenhouse gas emission intensities of the G7 nations? Energy Journal, 28, 145-169.

Belzer, D.B., Bender, S.R., Cort, K.A. (2017). A comprehensive system of energy intensity indicators for the U.S.: methods, data and key trends. Prepared by for U.S. Department of Energy by Pacific Northwest National Laboratory. Access at https://www.pnnl.gov/main/publications/external/technical_ reports/PNNL-22267.pdf.

Bergerson, J. A., Kofoworola, O., Charpentier, A. D., Sleep, S., \& MacLean, H. L. (2012). Life cycle greenhouse gas emissions of current oil sands technologies: Surface mining and in situ applications. Environmental Science and Technology, 46, 7865-7874.

Cansino, J. M., Sánchez-Braza, A., \& Rodríguez-Arévalo, M. L. (2015). Driving forces of Spain's $\mathrm{CO}_{2}$ emissions: a LMDI decomposition approach. Renewable and Sustainable Energy Reviews, 48, 749-759. https://doi.org/10.1016/j. rser.2015.04.011.

CIEEDAC. (2015). Canadian Industrial Energy End-Use Data and Analysis Centre (CIEEDAC) database on energy, production and intensity indicators for Canadian industry. Access http://www.sfu.ca/cieedac.html

Colinet Carmona, M. J., \& Román Collado, R. (2016). LMDI decomposition analysis of energy consumption in Andalusia (Spain) during 2003-2012: the energy efficiency policy implications. Energy Efficiency, 9, 807-823. https://doi. org/10.1007/s12053-015-9402-y.

Fernández González, P. (2015). Exploring energy efficiency in several European countries: an attribution analysis of the Divisia structural change index. Applied Energy, 137, 364 374.

IEA. (2016). Energy efficiency market report 2016. Paris: International Energy Agency, OECD.

Kerimray, A., Kolyagin, I., \& Suleimenov, B. (2017). Analysis of the energy intensity of Kazakhstan: from data compilation to decomposition analysis. Energy Efficiency, 11, 315-335. https://doi.org/10.1007/s12053-017-9565-9.

Moshiri, S., \& Duah, N. (2016). Changes in energy intensity in Canada. Energy Journal, 37(4), 315-343. https://doi. org/10.5547/01956574.37.4.smos.

Moutinho, V., Madaleno, M., \& Silva, P. M. (2016). Which factors drive $\mathrm{CO}_{2}$ emissions in EU-15? Decomposition and innovative accounting. Energy Efficiency, 9, 1087-1113. https://oi.org/10.1007/s12053-015-9411-x.

Nanduri, M., Nyboer, J., \& Jaccard, M. (2002). Aggregating physical intensity indicators - results of applying the composite indicator approach to the Canadian industrial sector. Energy Policy, 30, 151-163.

Norman, J. B. (2017). Measuring improvements in industrial energy efficiency: a decomposition analysis applied to the U.K. Energy, 137, 1144-1151. https://doi.org/10.1016/j. energy.2017.04.163.

NRCan. (2016). Energy efficiency trends in Canada 1990-2013. Office of Energy Efficiency (OEE), Natural Resources Canada (NRCan). Access at http://www.nrcan.gc. ca/energy/publications/19030.

O’Mahony, T., Zhou, P., \& Sweeney, J. (2012). The driving forces of change in energy-related $\mathrm{CO}_{2}$ emissions in Ireland: a multi-sector decomposition from 1990 to 2007. Energy Policy, 44, 256-267.

Oh, I., Wehrmeyer, W., \& Mulugetta, Y. (2010). Decomposition analysis and mitigation strategies of $\mathrm{CO}_{2}$ emissions from energy consumption in South Korea. Energy Policy, 38, 364-377. https://doi. org/10.1016/j.enpol.2009.09.027.

Olanrewaju, O.A. (2017). Energy consumption in South African industry: a decomposition analysis using the LMDI approach. Energy \& Environment, 29(2), 232-244. https://doi. org/10.1177/0958305X17745364.

Palmer, J. (2003). Decomposition of changes in energy use: the comparison of two approaches from a Canadian perspective. Proceedings, 2003 ACEEE Summer Study on Energy Efficiency in Industry, 6, 150-158.

Reutters, M., Patel, M. K., \& Eichhammer, W. (2017). Applying ex-post index decomposition analysis to primary energy consumption for evaluating progress towards European energy efficiency targets. Energy Efficiency, 10, 1381-1400. https://doi.org/10.1007/s12053-017-9527-2.

Shahiduzzaman, M. D., \& Layton, A. (2017). Decomposition analysis for assessing the United States 2025 emissions target: how big is the challenge? Renewable and Sustainable Energy Reviews, 67, 372-383. https://doi.org/10.1016/j. rser.2016.08.042.

Statistics Canada. (2015a). Canadian Socio-economic Information Management System (CANSIM). Access at http://www5. statcan.gc.ca/cansim/home-accueil?lang=eng.

Statistics Canada. (2015b). North American Industry Classification System (NAICS). Access at http://www. statcan.gc.ca/eng/subjects/standard/naics/2012/index.

$\mathrm{Su}$, B., \& Ang, B. W. (2012). Structural decomposition analysis applied to energy and emissions: Some methodological developments. Energy Economics, 34, 177188 .

Sumabat, A. K., Lopez, N. S., Yu, K. D., Hao, H., Li, R., Geng, Y., \& Chiu, A. S. F. (2016). Decomposition analysis of Philippine $\mathrm{CO}_{2}$ emissions from fuel combustion and electricity generation. Applied Energy, 164, 795-804. https://doi. org/10.1016/j.apenergy.2015.12.023.

Torrie, R. D., Stone, C., \& Layzell, D. B. (2016). Understanding energy systems change in Canada: 1. Decomposition of total energy intensity. Energy Economics, 56, 101-106.

Wang, M., \& Feng, C. (2017). Decomposition of energy-related $\mathrm{CO}_{2}$ emissions in China: an empirical analysis based on 
provincial panel data of three sectors. Applied Energy, 190, 772-787. https://doi.org/10.1016/j.apenergy.2017.01.007.

whatIf? Technologies. (2015). CanESS (Canadian Energy Systems Simulator). Access at http://www. whatiftechnologies.com.

Xu, X. Y., \& Ang, B. W. (2014). Multi-level index decomposition analysis: approaches and application. Energy Economics, 44, 375-382.
Zhang, W., Li, K., Zhou, D., Zhang, W., \& Gao, H. (2016). Decomposition of intensity of energy-related $\mathrm{CO}_{2}$ emissions in Chinese provinces using the LMDI method. Energy Policy, 92, 369-381. https://doi.org/10.1016/j. enpol.2016.02.026. 